NBSIR 82-2572

\title{
Status of Electron Transport Cross Sections
}

U.S. DEPARTMENT OF COMMERCE National Bureau of Standards

Washington, DC 20234

September 1982

Prepared for:

Office of Naval Research

Arlington, Virginia 22217

Space Science Data Center

NASA Goddard Space Flight Center

Greenbelt, Maryland 20771

Office of Health and Environmental Research

$-Q C$

Department of Energy

Washington, DC 20545 



\section{STATUS OF ELECTRON TRANSPORT CROSS SECTIONS}

S. M. Seltzer and M. J. Berger

U.S. DEPARTMENT OF COMMERCE

National Bureau of Standards

Washington, DC 20234

September 1982

Prepared for:

Office of Naval Research

Arlington, Virginia 22217

Space Science Data Center

NASA Goddard Space Flight Center

Greenbelt, Maryland 20771

Office of Health and Environmental Research

Department of Energy

Washington, DC 20545

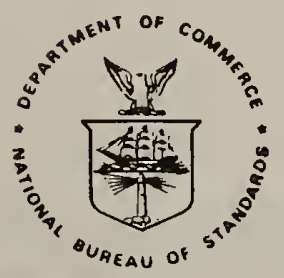

U.S. DEPARTMENT OF COMMERCE, Malcolm Baldrige, Secretary NATIONAL BUREAU OF STANDARDS, Ernest Ambler, Director 



\title{
Status of Electron Transport Cross Sections ${ }^{*}$
}

\author{
Stephen M. Seltzer and Martin J. Berger \\ National Bureau of Standards \\ Washington, D.C. 20234
}

This report describes recent developments and improvements pertaining to cross sections for electron-photon transport calculations. The topics discussed include: (1) electron stopping power (mean excitation energies, density-effect correction); (2) bremsstrahlung production by electrons (radiative stopping power, spectrum of emitted photons); (3) elastic scattering of electrons by atoms; (4) electron-impact ionization of atoms.

Key words: bremsstrahlung; cross sections; elastic scattering; electronimpact ionization; electrons; photons; stopping power; transport.

* Summary of a paper presented at the Annual Meeting of the American Nuclear Society, June $7-11,1982$, Los Angeles, California.

This work was supported by the Office of Naval Research, by the National space Science Data Center at the NASA Goddard Space Flight Center, and by the Office of Health and Environmental Research of the Department of Energy. 

Status of Electron Transport Cross Sections ${ }^{*+}$

\author{
Stephen M. Seltzer and Martin J. Berger \\ National Bureau of Standards \\ Washington, D.C. 20234
}

This report describes recent developments and improvements pertaining to cross sections for electron-photon transport calculations. The topics discussed include: (1) electron stopping power (mean excitation energies, density-effect correction); (2) bremsstrahlung production by electrons (radiative stopping power, spectrum of emitted photons); (3) elastic scattering of electrons by atoms; (4) electron-impact ionization of atoms.

Key words: bremsstrahlung; cross sections; elastic scattering; electronimpact ionization; electrons; photons; stopping power; transport.

* Summary of a paper presented at the Annual Meeting of the American Nuclear Society, June 7-11, 1982, Los Angeles, California.

This work was supported by the Office of Naval Research, by the National Space Science Data Center at the NASA Goddard Space Flight Center, and by the Office of Health and Environmental Research of the Department of Energy. 


\section{INTRODUCTION}

In this paper we highlight certain improvements to the cross-section data base for various Monte Carlo computer codes such as ETRAN [1], ', EGS [2], SANDYL [3], TIGER [4], ACCEPT [5], etc., which are used to calculate the transport of electrons and associated bremsstrahlung at energies from $\sim 10 \mathrm{keV}$ up to $1 \mathrm{GeV}$. The discussion will be in terms of the cross-section information needed by the ETRAN code [1], as supplied by the program DATAPAC [6], but is also applicable to the SANDYL, TIGER, and ACCEPT codes which are decendants of ETRAN.

\section{ELECTRON STOPPING POWER}

\subsection{Mean excitation energies}

We have completed a critical review of the mean excitation energy I, the key quantity in the Bethe theory of the collision stopping power. Based on current information derived from stopping-power and range data, oscillator-strength distributions for gases, and dielectric-response functions for condensed media, I-values were selected for 43 elemental substances and 54 compounds. I-values for other elements were obtained by interpolation with respect to atomic number (see table 1 and fig. 1). I-values for other compounds were obtained through the application of the Bragg additivity rule, using I-values for atomic constituents modified to take into account chemical binding and phase effects (see table 2). Further details can be found in references [7-9].

\subsection{Density-effect correction}

The density-effect correction, the other non-trivial quantity entering into the Bethe formula, was also re-examined. For this correction,. DATAPAC uses the algorithm of Sternheimer and Peierls [10], which is a universal fit to previously calculated results. The use of this fit involves some sacrifice in accuracy, and in recent work $[9,11]$ we have gone back to the numerical evaluation of the density effect using Sternheimer's [12] model in conjunction with updated values of mean excitation energies and atomic binding energies. We have found that our numerical results for the density effect are in good agreement with those calculated by Inokuti and Smith [13] for aluminum and by Ashley [14] for water with semi-empirical dielectric-response functions. The changes in the collision stopping power that result from using the new numerical results instead of the Sternheimer-Peierls algorithm are shown in figure 2 for selected materials.

${ }^{1}$ Numbers in brackets indicate the literature references at the end of this paper. 


\subsection{Conclusions}

(i) The analysis of experimental data confirms the theoretical prediction [15] that, due to atomic shell effects, $I / Z$ is an irregular function of $Z$. (ii) The Bragg additivity rule, with a simple assignment of I-values for atomic constituents that takes into account chemical binding and phase effects, provides an accurate representation of the I-values for over 50 compounds and is expected to be a reliable method for predicting I-values for other materials. (iii) The combined effect of using the new I-values and density-effect corrections results in changes of no more than $3-4 \%$, more typically $1-2 \%$, in the collision stopping power as compared to our older values from DATAPAC.

\section{BREMSSTRAHLUNG PRODUCTION BY ELECTRONS}

\subsection{Radiation stopping power}

As discussed in reference [16], DATAPAC makes use of a combination of BetheHeitler Born-approximation formulas, with empirical corrections, at energies below $50 \mathrm{MeV}$, and above $50 \mathrm{MeV}$ uses the exact high-energy theory of Davies, Bethe, Maximon, and 01 sen [17], which includes a Coulomb correction. A significant improvement in the calculation of the cross section for bremsstrahlung in the field of the screened nucleus was made by Pratt et az. [18], who solved the Dirac equation numerically for a static, screened Coulomb potential, and evaluated the bremsstrahlung matrix elements numerically from the wave functions. These authors give the cross section, differential in emitted photon energy, for atomic numbers $z$ from 2 to 92 and for electron kinetic energies from $1 \mathrm{keV}$ to $2 \mathrm{MeV}$.

For the calculation of electron radiative stopping powers $[9,19]$, we have bridged the gap between 2 and $50 \mathrm{MeV}$ by interpolating between the results of Pratt et al. and the results from the high-energy theory. Two additional improvements were also made: (a) the high-energy results were re-evaluated using screening functions based on Hartree-Fock rather than Thomas-Fermi form factors; (b) the contribution from bremsstrahlung produced in the field of the atomic electrons was evaluated on the basis of Haug's [20] cross section. The results can be convenientiy summarized in terms of the scaled radiative energy-loss functions

$$
\phi_{r a d}^{(n)}(T)=\frac{1}{a r_{e}^{2}} \frac{1}{T+m c^{2}} \int_{0}^{T} \frac{k}{z^{2}} \frac{d \sigma^{(n)}(k, T)}{d k} d k \quad \text { (electron-nucleus) }
$$

and 


$$
\phi_{\operatorname{rad}}^{(e)}(T)=\frac{1}{a r_{e}^{2}} \frac{1}{T+m c^{2}} \int_{0}^{T^{\prime}} \frac{k}{Z} \frac{d \sigma^{(e)}(d, T)}{d k} d k \quad \text { (electron-electron), }
$$

where $\alpha$ is the fine structure constant $(1 / 137.03604), r_{e}$ is the classical electron radius $\left(2.817938 \times 10^{-13} \mathrm{~cm}\right), \mathrm{mc}^{2}$ is the electron rest mass $(0.5110034 \mathrm{MeV})$, $Z$ is the atomic number, $T$ is the electron kinetic energy, $\frac{d \sigma}{d k}$ is the bremsstrahlung production cross section differential in emitted photon energy $k$, either in the field of the atomic nucleus (denoted by superscript $n$ ) or in the field of the atomic electrons (denoted by superscript e), and $T^{\prime}=m c^{2} T /\left[T+2 m c^{2}-\left(T\left(T+2 m c^{2}\right)\right)^{\frac{1}{2}}\right]$ is the maximum possible energy of photons emitted in an electron-electron collision. The radiative stopping power can then be written as

$$
\frac{1}{\rho}\left(\frac{d E}{d x}\right)_{\operatorname{rad}}=\frac{N_{a}}{A} \alpha r_{e}^{2}\left(T+m c^{2}\right) z^{2} \phi_{r a d}^{(n)}(T)\left[1+\frac{1}{z} \frac{\phi_{\text {rad }}^{(e)}(T)}{\phi_{r a d}^{(n)}(T)}\right] \text {, }
$$

where $\mathrm{N}_{\mathrm{a}}$ is Avagadro's number $\left(6.022045 \times 10^{23} \mathrm{~mol}^{-1}\right)$ and $A$ is the atomic weight of the material. Figure 3 gives results for $\phi_{\mathrm{rad}}^{(n)}$ from $1 \mathrm{keV}$ to $10 \mathrm{GeV}$ in selected materials. The ratio $\phi_{\mathrm{rad}}^{(\mathrm{e})}(T) / \phi_{\mathrm{rad}}^{(n)}(T)$, previously assumed equal to unity in DATAPAC, is shown in figure 4 for hydrogen, carbon, and gold. At high energies, this ratio is greater than unity due to the differences in screening and Coulomb effects between the electron-electron and the electron-nucleus systems. At low energies, the ratio tends to vanish due to the lack of a dipole moment for the electron-electron system.

\subsection{Spectrum of emitted photons}

A similar synthesis for the cross section differential in emitted photon energy is in progress. A further refinement is included to account for the non-zero value of the electron-nucleus cross section at the high-frequency limit (tip of the bremsstrahlung spectrum, $k=T$ ). This is accomplished (a) by interpolating between the tip values predicted by Jabbur and Pratt [21] for extremely high energies and those given by Pratt et al. [18] for energies below $2 \mathrm{MeV}$, as illustrated in figure 5; and (b) by applying a Coulomb correction, shown in figure 6 , which combines the results of Davies, Bethe, Maximon, and 01sen [17] with the Elwert [22] factor so as to insure that the cross section goes smoothly into the tip value. Figures $7 a$ and $b$ give the cross sections at $50 \mathrm{MeV}$ for carbon and gold, and are typical of the highenergy $(T \geqslant 50 \mathrm{MeV})$ results; figures $7 \mathrm{c}$ and $d$, for carbon and gold at $50 \mathrm{keV}$, illustrate the results for $T \leqslant 2 \mathrm{MeV}$. The accuracy of the interpolated results in 
the gap region from 2 to $50 \mathrm{MeV}$ is confirmed by the comparisons, shown in figures $8 \mathrm{a}$ and $b$, with the results available from the exploratory, exact numerical calculations of Tseng and Pratt [23], for $\mathrm{Al}$ and $\mathrm{U}$ at 5 and $10 \mathrm{MeV}$.

\subsection{Conclusions}

The use of the cross sections of Pratt et az., together with interpolation linking the low- and high-energy theories, results in a significant improvement over the cross-section package and empirical correction factors used in DATAPAC. The procedures outlined above will provide the basis for a planned comprehensive tabulation of bremsstrahlung cross sections for electron energies greater than $2 \mathrm{MeV}$.

\section{ELECTRON ELASTIC SCATTERING}

\subsection{Discussion of cross sections}

The accurate evaluation of the elastic scattering cross section requires - in principle - exact phase shift calculations for the solution of the Dirac equation for the electron in a screened Coulomb potential. In practice, an approximation is - in most cases - quite adequate in which the cross section is calculated as the product of two factors: (a) the unscreened Mott [24] cross section which includes spin and relativistic effects; and (b) a screening correction term.

We have considered two methods of calculating the screening factor. The first method, introduced by Spencer [25] and used in DATAPAC, consists of using the factor $(1-\cos \theta)^{2} /(1-\cos \theta+2 n)^{2}$ where $n$ is an energy- and $Z$-dependent screening parameter derived by Moliere [26] in a calculation for the Thomas-Fermi atom. The second method consists of using the impulse approximation in which the screening factor is taken to be $[1-F(q, Z)]^{2}$, where $F(q, Z)$ is a Hartree-Fock atomic form factor for momentum transfer $q$ and atomic number $Z$.

At low energies the factorization of the elastic scattering cross section becomes inaccurate (see, e.g., Zeitler and 01 sen [27]), and it becomes necessary to carry out a full phase-shift analysis. The most comprehensive calculations of this kind are those of Riley et al. [28], who give results at 9 energies from 1 to $256 \mathrm{keV}$ and for selected elements from $Z=2$ to 92 , and who also give a convenient approximation for $Z=1-94$ which facilitates the incorporation of their cross sections into DATAPAC (see also Haggmark et az. [29]).

We have investigated the validity of the factorization in terms of the transport (or momentum transfer) cross section $\sigma_{1}=\sigma(1-\overline{\cos \theta})$, where $\sigma$ is the total cross section (integrated over all angles) and $\overline{\cos \theta}$ is the mean cosine of the scattering angle. As pointed out by Moliere [26] and by Bethe [30], the transport cross section 
has the dominant influence on the multiple elastic scattering process. In figure 9 we compare the transport cross sections of Riley et al. with those from the MoliereMott approximation and those from the impulse approximation.

\subsection{Conclusions}

(i) Comparisons with the exact results of Riley et al. indicate that the Moliere-Mott approximation used in DATAPAC begins to break down, in terms of the transport cross section, at electron energies below $\sim 128 \mathrm{keV}$ in $\mathrm{Au}, \sim 64 \mathrm{keV}$ in $\mathrm{Cu}, \sim 16 \mathrm{keV}$ in $\mathrm{Al}$, and $\sim 4 \mathrm{keV}$ in Be. (ii) To the extent that transport calculations depend only on the transport cross section, the data of Riley et al. and/or the results from the Moliere-Mott approximation provide sufficient data at all energies. However, it would be desirable to extend the exact calculations to energies somewhat higher than $256 \mathrm{keV}$ for the high-Z elements. (iii) The incorporation of the exact cross sections into the multiple scattering algorithm in DATAPAC could be greatly simplified by retaining the Moliere-Mott approximation, but adjusting the screening parameter $n$ so as to obtain the correct value of the transport cross section $\sigma_{1}$. The accuracy of this approximation remains to be investigated.

\section{ELECTRON-IMPACT IONIZATION}

\subsection{Discussion of cross sections}

As an energy-loss mechanism, this process is included in the collision stopping power. Knowledge of ionization cross section is needed when including in a transport calculation the emission of $x$ rays subsequent to ionizations of inner shells. Numerous calculations of this cross section, done in various approximations, have been reported. In DATAPAC, we have used the approximate formula of Kolbenstvedt [31] for K-shell ionization, which was derived by the Weizsäcker-Williams method. Recently, the $a b$ initio calculations of Scofield [32] have become available for the $K$ and $L$ shells, for $Z \geqslant 18$, and for $T \geqslant 50 \mathrm{keV}$. We have applied the Weizsäcker-Williams method for all shells, going beyond Kolbenstvedt through the use of more detailed theoretical and experimental photoionization cross sections for soft collisions and through the use of binary-encounter theory for hard collisions. In figures 10 and 11 we compare results from Scofield and from our Weizsäcker-Williams calculations with experimental data [33-51] for $\mathrm{Au}, \mathrm{Ni}$, and $\mathrm{Al}$. 


\subsection{Conclusions}

(i) The results obtained by our application of the Weizsäcker-Williams method agree quite well with experiment and with Scofield's rigorous results at energies above about 20 times the ionization threshold energy. (ii) At energies below $\sim 20$ times the ionization threshold energy, the Weizsäcker-Williams results appear to be more consistent with experimental data than Scofield's results. (iii) The WeizsäckerWilliams method, which requires a modest computational effort, can be used to extend coverage to any energy, atom, and shell of interest (for example, for $z<18$ not covered by Scofield). It is a useful alternative to semi-empirical methods for estimating the electron-impact ionization cross section, such as the formula of Lotz [52].

\section{REFERENCES}

[1] M. J. Berger and S. M. Seltzer, National Bureau of Standards Report 9837 (1968); see also Oak Ridge National Laboratory Publ. ORNL-RSIC Report CCC-107 (1968).

[2] R. L. Ford and W. R. Nelson, Stanford Linear Accelerator Center Report SLAC-210, UC-32 (1978).

[3] H. M. Colbert, Sandia Laboratories Report SLL-74-0012 (1973).

[4] J. A. Halbleib and W. H. Vandevender, Sandia Laboratories Report SLA-73-1026 (1974).

[5] J. A. Halbleib, Sandia Laboratories Report SAND79-0415 (1979).

[6] M. J. Berger and S. M. Seltzer, National Bureau of Standards Report 9836 (1968); a'1 so Oak Ridge National Laboratory Publ. ORNL-RSIC Report CCC-107 (1968).

[7] S. M. Seltzer and M. J. Berger, Intl. J. of Applied Radiation and Isotopes, in press.

[8] M. J. Berger and S. M. Seltzer, Proc. of the Seminar on Charge States and Dynamic Screening of Swift Ions in Solids, Honolulu, Hawaii, Jan. 25-29 (1982), to be published.

[9] M. J. Berger and S. M. Seltzer, National Bureau of Standards Report NBSIR 82-2550 (1982).

[10] R. M. Sternheimer and R. F. Peierls, Phys. Rev. B $\underline{3}, 3681$ (1971).

[11] R. M. Sternheimer, S. M. Seltzer, and M. J. Berger, submitted to Phys. Rev.

[12] R. M. Sternheimer, Phys. Rev. 88, 851 (1952). 
[13] M. Inokuti and D. Y. Smith, Phys. Rev. B 25, 61 (1982).

[14] J. C. Ashley, Rad. Res. 89, 32 (1982).

[15] W. K. Chu and D. Powers, Phys. Lett. 40A, 23 (1972).

[16] M. J. Berger and S. M. Seltzer, Phys. Rev. C 2 , 621 (1970).

[17] H. Davies, H. A. Bethe and L. C. Maximon, Phys. Rev. 93, 788 (1954);

H. 01 sen, Phys. Rev. 99, 1335 (1955).

[18] R. H. Pratt, H. K. Tseng, C. M. Lee, L. Kissel, C. MacCallum, and M. Riley, Atomic Data and Nuclear Data Tables 20, 175 (1977); errata in 26, 477 (1981); see also revised data in L. Kissel, C. MacCallum, and R. H. Pratt, Sandia National Laboratories Report SAND81-1337 (1981).

[19] S. M. Seltzer and M. J. Berger, Intl. J. of Applied Radiation and Isotopes, in press.

[20] E. Haug, Z. f. Naturforsch. 30a, 1099 (1975).

[21] R. J. Jabbur and R. H. Pratt, Phys. Rev. 129, 184 (1963); Phys. Rev. 133, B1090 (1964).

[22] G. Elwert, Ann. Physik. 34, 178 (1939).

[23] H. K. Tseng and R. H. Pratt, Phys. Rev. A 19,1525 (1979).

[24] N. F. Mott and H. S. W. Massey, The Theory of Atomic Collisions (Oxford University Press, London), 2nd edition (1949).

[25] L. V. Spencer, National Bureau of Standards Monograph 1 (1959).

[26] G. Moliere, Z. Naturforsch. 3a, 78 (1948).

[27] E. Zeitler and H. 01sen, Phys. Rev. 136, A1546 (1964).

[28] M. E. Riley, C. J. MacCallum, and F. Biggs, Atomic Data and Nuclear Data Tables 15, $443(1975)$.

[29] L. G. Haggmark, C. J. McCallum, and M. E. Riley, Trans. Am. Nucl. Soc. 19, 471 (1974).

[30] H. A. Bethe, Phys. Rev. 89, 1256 (1953).

[31] H. Kolbenstvedt, J. Appl. Phys. 38, 4785 (1967).

[32] J. H. Scofield, Phys. Rev. A 18, 963 (1978).

[33] L. M. Middleman, R. L. Ford, and R. Hofstader, Phys. Rev. A 2, 1429 (1970).

[34] K. Ishii, M. Kamiya, K. Sera, S. Morita, H. Tawara, M. Oyamada, and T. C. Chu, Phys. Rev. A 15, 906 (1977).

[35] H. H. Hoffmann, H. Genz, W. Löw, and A. Richter, Phys. Lett. 65A, 304 (1978).

[36] G. R. Dangerfield and B. M. Spicer, J. Phys. B $\underline{8}, 1744$ (1975). 
[37] K. H. Berkner, S. N. Kaplan, and R. V. Pyle, Bull. Am. Phys. Soc. 15, 786 (1970).

[38] D. H. Rester and W. E. Dance, Phys. Rev. 152, 1 (1966).

[39] H. Hansen and A. Flammersfeld, Nucl. Phys. 79, 135 (1966).

[40] J. W. Motz and R. C. Placious; Phys. Rev. 136, A662 (1964).

[41] D. V. Davis, V. D. Mistry, and C. A. Quarles, Phys. Lett. 35A, 169 (1972).

[42] S. I. Salem and L. D. Moreland, Phys. Lett. 37A, 161 (1971).

[43] M. Green, Ph.D. Dissertation, Univ. of Cambridge, Cambridge, England (1962); data obtained from reference 42.

[44] Y. K. Park, M. T. Smith, and W. Scholz, Phys. Rev. A 12, 1358 (1975).

[45] W. Hink and A. Ziegler, Z. Physik 226, 222 (1969).

[46] H. Genz, C. Brendel, P. Eschwey, U. Kuhn, W. Löw, A. Richter, P. Seserko, and R. Sauerwein, Institute für Kernphysik, Technische Hochschule Darmstadt, Report IKDA 81/16 (August, 1981).

[47] A. Li-Scholz, R. Colle, I. L. Preiss, and W. Scholz, Phys. Rev. A I, 1957 (1973).

[48] S. A. H. Seif el Nasr, D. Berenyi, and Gy. Bibok, Z. Physik 267, 169 (1974).

[49] L. T. Pockman, D. L. Webster, P. Kirkpatrick, and K. Harwort, Phys. Rev. 71, $330(1947)$.

[50] A. E. Smick and P. Kirkpatrick, Phys. Rev. 67, 153 (1945).

[51] J. Jessenberger and W. Hink, Z. Physik A 275, 331 (1975).

[52] W. Lotz, Z. Physik 232, 101 (1970).

[53] N. E. Holden, Pure and Appl. Chem. 51, 405 (1979).

[54] J. F. Ziegler, Handbook of Stopping Cross Sections for Energetic Ions in all Elements, Vol. 5, Pergamon Press, New York (1980).

[55] J. H. Hubbel1, W. J. Veigele, E. A. Briggs, R. T. Brown, D. T. Cromer, and R. J. Howerton, J. Phys. Chem. Ref. Data $\underline{4}, 471$ (1975); errata in $\underline{6}, 615$ (1977).

[56] J. H. Hubbell and I. J. Qverbø, J. Phys. Chem. Ref. Data $\underline{8}, 69$ (1979).

[57] J. A. Wheeler and W. E. Lamb, Phys. Rev. 55, 858 (1939); errata in 101, 1836 (1956). 
Table 1. Values of the mean excitation energy I for the elements. Unless noted otherwise, the values are for the substance in the condensed phase.

\begin{tabular}{|c|c|c|c|c|}
\hline$\underline{z}$ & Element & Symbol & $\underline{\mathrm{A},{ }^{a} \mathrm{~g} / \mathrm{mol}}$ & $\underline{\mathrm{I}, b} \mathrm{eV}$ \\
\hline 1 & hydrogen & H & 1.0079 & $\begin{array}{l}19.2 \pm 0.4 \text { molecular gas } \\
21.8 \pm 1.6 \text { liquid }\end{array}$ \\
\hline 2 & helium & $\mathrm{He}$ & 4.00260 & $41.8 \pm 0.8$ gas \\
\hline 3 & lithium & Li & 6.941 & $40 \pm 5$ \\
\hline 4 & beryllium & $\mathrm{Be}$ & 9.01218 & $63.7 \pm 3.0$ \\
\hline 5 & boron & B & 10.81 & $76.0 \pm 8.0$ \\
\hline 6 & carbon & c & 12.011 & $78.0 \pm 7.0$ graphite \\
\hline 7 & nitrogen & N & 14.0067 & $82.0 \pm 2.0$ molecular gas \\
\hline 8 & oxygen & 0 & 15.9994 & $95.0 \pm 2.0$ molecular gas \\
\hline 9 & fluorine & $F$ & 18.998403 & $(115 \pm 10)$ gas \\
\hline 10 & neon & $\mathrm{Ne}$ & 20.179 & $137 \pm 4$ gas \\
\hline 11 & sodium & $\mathrm{Na}$ & 22.98977 & $(149 \pm 10)$ \\
\hline 12 & magnesium & $\mathrm{Mg}$ & 24.305 & $(156 \pm 10)$ \\
\hline 13 & a luminum & Al & 26.98154 & $166 \pm 2$ \\
\hline 14 & silicon & Si & 28.0855 & $173 \pm 3$ \\
\hline 15 & phosphorus & $P$ & 30.97376 & $(173 \pm 15)$ \\
\hline 16 & sulfur & $S$ & 32.06 & $(180 \pm 15)$ \\
\hline 17 & chlorine & $\mathrm{Cl}$ & 35.453 & $(174 \pm 15)$ gas \\
\hline 18 & argon & $\mathrm{Ar}$ & 39.948 & $188 \pm 10$ gas \\
\hline 19 & potassium & $k$ & 39.0983 & $(190 \pm 15)$ \\
\hline 20 & calcium & $\mathrm{Ca}$ & 40.08 & $191 \pm 8$ \\
\hline 21 & scandium & Sc & 44.9559 & $216 \pm 8$ \\
\hline 22 & titanium & $\mathrm{Ti}$ & 47.88 & $233 \pm 5$ \\
\hline 23 & vanadium & V & 50.9415 & $245 \pm 7$ \\
\hline 24 & chromium & $\mathrm{Cr}$ & 51.996 & $257 \pm 10$ \\
\hline 25 & manganese & Mn & 54.9380 & $272 \pm 10$ \\
\hline 26 & iron & $\mathrm{Fe}$ & 55.847 & $286 \pm 9$ \\
\hline 27 & cobalt & Co & 58.9332 & $297 \pm 9$ \\
\hline 28 & nickel & $\mathrm{Ni}$ & 58.69 & $311 \pm 10$ \\
\hline 29 & copper & $\mathrm{Cu}$ & 63.546 & $322 \pm 10$ \\
\hline 30 & zinc & $\mathrm{Zn}$ & 65.38 & $330 \pm 10$ \\
\hline 31 & gallium & $\mathrm{Ga}$ & 69.72 & $(334 \pm 20)$ \\
\hline 32 & germanium & $\mathrm{Ge}$ & 72.59 & $350 \pm 11$ \\
\hline 33 & arsenic & As & 74.9216 & $(347 \pm 25)$ \\
\hline
\end{tabular}




\begin{tabular}{|c|c|c|c|c|}
\hline z & Element & Symbol & $\mathrm{A},{ }^{a} \mathrm{~g} / \mathrm{mol}$ & $\mathrm{I}, b \mathrm{eV}$ \\
\hline 34 & selenium & $\mathrm{Se}$ & 78.96 & $(348 \pm 30)$ \\
\hline 35 & bromine & $\mathrm{Br}$ & 79.904 & $\begin{array}{l}(343 \pm 30) \text { gas } \\
(357 \pm 30) \text { condensed }\end{array}$ \\
\hline 36 & krypton & $\mathrm{kr}$ & 83.80 & $352 \pm 25$ gas \\
\hline 37 & rubidium & $\mathrm{Rb}$ & 85.4678 & $(363 \pm 30)$ \\
\hline 38 & strontium & $s r$ & 87.62 & $(366 \pm 30)$ \\
\hline 39 & yttrium & Y & 88.9059 & $(379 \pm 30)$ \\
\hline 40 & zirconium & $\mathrm{Zr}$ & 91.22 & $393 \pm 15$ \\
\hline 41 & niobium & $\mathrm{Nb}$ & 92.9064 & $417 \pm 15$ \\
\hline 42 & molybdenum & Mo & 95.94 & $424 \pm 15$ \\
\hline 43 & technetium & ${ }^{98} \mathrm{TC}$ & 97.907 & $(428 \pm 35)$ \\
\hline 44 & ruthenium & $\mathrm{Ru}$ & 101.07 & $(441 \pm 35)$ \\
\hline 45 & rhodium & $\mathrm{Rh}$ & 102.9055 & $449 \pm 20$ \\
\hline 46 & palladium & $\mathrm{Pd}$ & 106.42 & $470 \pm 20$ \\
\hline 47 & silver & $\mathrm{Ag}$ & 107.868 & $470 \pm 10$ \\
\hline 48 & cadmi um & $\mathrm{Cd}$ & 112.41 & $469 \pm 20$ \\
\hline 49 & indium & In & 114.82 & $488 \pm 20$ \\
\hline 50 & tin & Sn & 118.69 & $488 \pm 15$ \\
\hline 51 & antimony & Sb & 121.75 & $(487 \pm 40)$ \\
\hline 52 & tellurium & $\mathrm{Te}$ & 127.60 & $(485 \pm 40)$ \\
\hline 53 & iodine & I & 126.9045 & $\begin{array}{l}(474 \pm 40) \text { gas } \\
(491 \pm 40) \text { condensed }\end{array}$ \\
\hline 54 & xenon & $\mathrm{Xe}$ & 131.29 & $482 \pm 30$ gas \\
\hline 55 & cesium & Cs & 132.9054 & $(488 \pm 40)$ \\
\hline 56 & barium & $\mathrm{Ba}$ & 137.33 & $(491 \pm 40)$ \\
\hline 57 & lanthanum & La & 138.9055 & $(501 \pm 40)$ \\
\hline 58 & cerium & $\mathrm{Ce}$ & 140.12 & $(523 \pm 40)$ \\
\hline 59 & praseodymium & $\mathrm{Pr}$ & 140.9077 & $(535 \pm 45)$ \\
\hline 60 & neodymium & $\mathrm{Nd}$ & 144.24 & $(546 \pm 45)$ \\
\hline 61 & promethium & ${ }^{145} \mathrm{Pm}$ & 144.913 & $(560 \pm 45)$ \\
\hline 62 & samarium & Sm & 150.36 & $(574 \pm 45)$ \\
\hline 63 & europium & $\mathrm{Eu}$ & 151.96 & $(580 \pm 45)$ \\
\hline 64 & gadolinium & Gd & 157.25 & $591 \pm 50$ \\
\hline 65 & terbium & $\mathrm{Tb}$ & 158.9254 & $(614 \pm 55)$ \\
\hline 66 & dysprosium & Dy & 162.50 & $(628 \pm 55)$ \\
\hline 67 & holmium & Ho & 164.9304 & $(650 \pm 60)$ \\
\hline 68 & erbium & Er & 167.26 & $(658 \pm 60)$ \\
\hline 69 & thulium & $\mathrm{Tm}$ & 168.9342 & $(674 \pm 60)$ \\
\hline
\end{tabular}




\begin{tabular}{|c|c|c|c|c|}
\hline 2 & Element & Symbol & $\underline{\mathrm{A},{ }^{a} \mathrm{~g} / \mathrm{mol}}$ & $\underline{\mathrm{I}, b} \mathrm{eV}$ \\
\hline 70 & ytterbium & $\mathrm{Yb}$ & 173.04 & $(684 \pm 65)$ \\
\hline 71 & lutetium & Lu & 174.967 & $(694 \pm 65)$ \\
\hline 72 & hafnium & $\mathrm{Hf}$ & 178.49 & $(705 \pm 65)$ \\
\hline 73 & tantalun & $\mathrm{Ta}$ & 180.9479 & $718 \pm 30$ \\
\hline 74 & tungsten & W & 183.85 & $727 \pm 30$ \\
\hline 75 & rhenium & $\operatorname{Re}$ & 186.207 & $(736 \pm 70)$ \\
\hline 76 & osmium & Os & 190.2 & $(746 \pm 70)$ \\
\hline 77 & iridium & Ir & 192.22 & $757 \pm 30$ \\
\hline 78 & platinum & $P t$ & 195.08 & $790 \pm 30$ \\
\hline 79 & gold & $\mathrm{Au}$ & 196.9665 & $790 \pm 30$ \\
\hline 80 & mercury & $\mathrm{Hg}$ & 200.59 & $(800 \pm 75)$ \\
\hline 81 & thallium & $T \ell$ & 204.383 & $(810 \pm 75)$ \\
\hline 82 & lead & $\mathrm{Pb}$ & 207.2 & $823 \pm 30$ \\
\hline 83 & bismuth & $\mathrm{Bi}$ & 208.9804 & $(823 \pm 80)$ \\
\hline 84 & polonium & ${ }^{9}$ Po & 208.982 & $(830 \pm 80)$ \\
\hline 85 & astatine & ${ }^{210} \mathrm{At}$ & 209.987 & $(825 \pm 80)$ \\
\hline 86 & radon & ${ }^{222} \mathrm{Rn}$ & 222.018 & $(794 \pm 80)$ gas \\
\hline 87 & francium & ${ }^{223} \mathrm{Fr}$ & 223.020 & $(827 \pm 80)$ \\
\hline 88 & radium & $\mathrm{Ra}$ & 226.0254 & $(826 \pm 80)$ \\
\hline 89 & actinium & $A C$ & 227.0278 & $(841 \pm 80)$ \\
\hline 90 & thorium & Th & 232.0381 & $(847 \pm 80)$ \\
\hline 91 & protactinium & $\mathrm{Pa}$ & 231.0359 & $(878 \pm 80)$ \\
\hline 92 & uranium & U & 238.0289 & $890 \pm 30$ \\
\hline 93 & neptunium & $\mathrm{Np}$ & 237.0482 & $(902 \pm 80)$ \\
\hline 94 & plutonium & ${ }^{239} \mathrm{Pu}$ & 239.052 & $(921 \pm 85)$ \\
\hline 95 & americium & ${ }^{243} \mathrm{Am}$ & 243.061 & $(934 \pm 85)$ \\
\hline 96 & curium & ${ }^{247} \mathrm{Cm}$ & 247.070 & $(939 \pm 85)$ \\
\hline 97 & berkelium & ${ }^{247}{ }_{B K}$ & 247.070 & $(952 \pm 85)$ \\
\hline 98 & californium & ${ }^{251} \mathrm{Cf}$ & 251.080 & $(966 \pm 90)$ \\
\hline 99 & einsteinium & ${ }^{252}$ Es & 252.083 & $(980 \pm 90)$ \\
\hline 100 & fermium & ${ }^{257} \mathrm{Fm}$ & 257.095 & $(994 \pm 90)$ \\
\hline
\end{tabular}

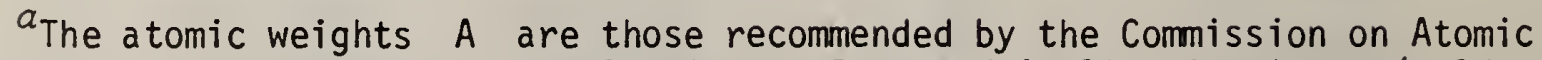
W'eights of the International Union of Pure and Applied Chemistry (Holden [53]). The values are for naturally occuring isotopic mixtures, unless a particular isotope is indicated.

${ }^{b}$ Values in parentheses are estimated by interpolation of $I / Z$ vs. $Z$, or by extrapolation for $Z>92$. 
Table 2. Mean excitation energies adopted in the present work for atomic constituents of compounds.

\begin{tabular}{cl}
\multicolumn{2}{c}{ GASES } \\
Constituent & \\
\cline { 1 - 1 } H & \\
C & 19.2 \\
N & 70 \\
O & 82 \\
& 97
\end{tabular}

\section{LIQUIDS AND SOLIDS}

Constituent

H

C

N

0

$\mathrm{F}$

$\mathrm{Cl}$

Others
$\underline{\mathrm{I}(\mathrm{eV})}$

19.2

81

82

106

112

180
$1.13 \times I$, where $I$ is the I-value for the element in the condensed phase given in Table 1. 


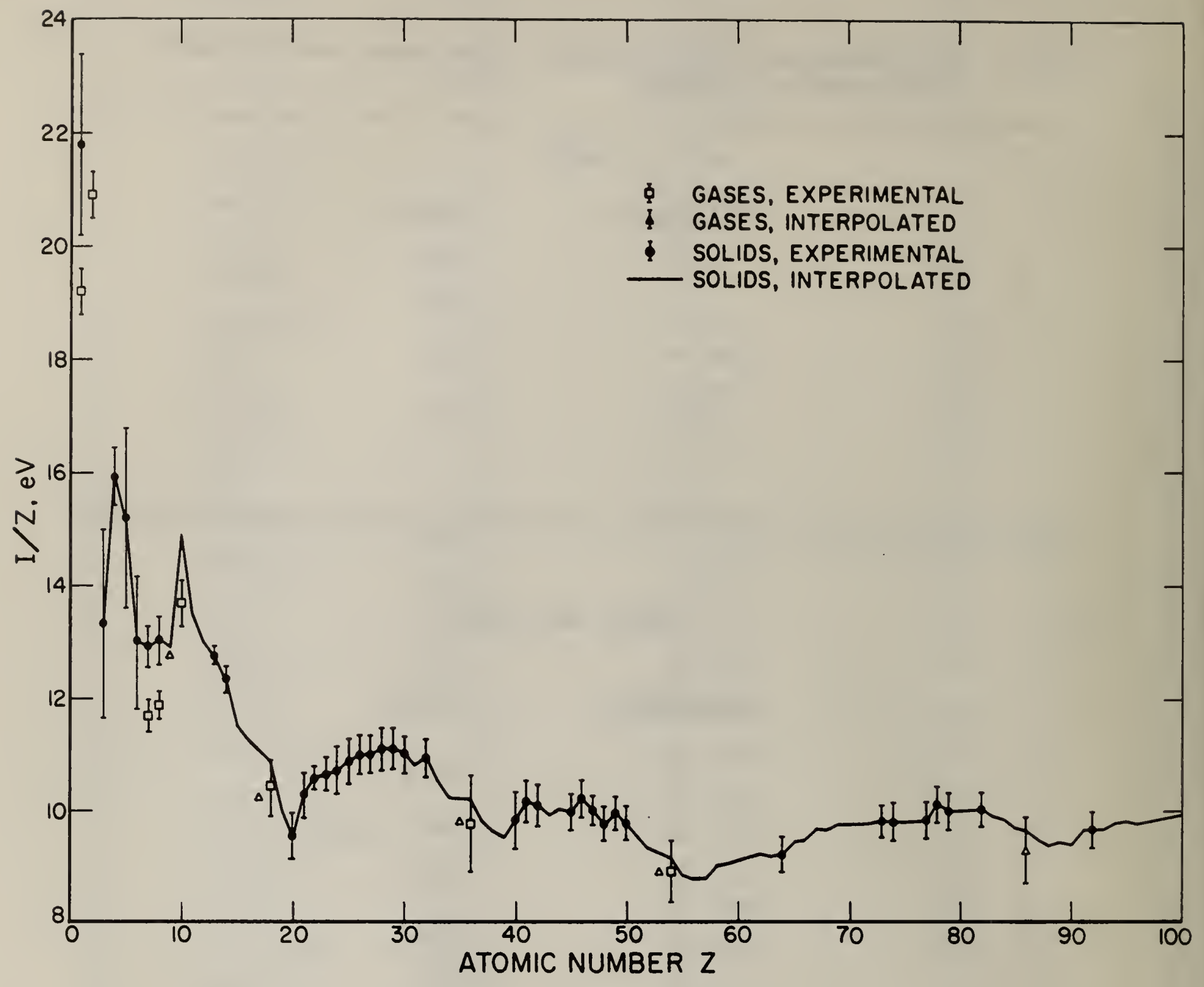

Fig. 1. Ratio of the mean excitation energy I to the atomic number $Z$ for elements. Points indicated as experimental are the result of a critical analysis of experimental data; interpolated results are based in part on the theoretical results of Chu and Powers [15] for gases or of Ziegler [54] for solids. 


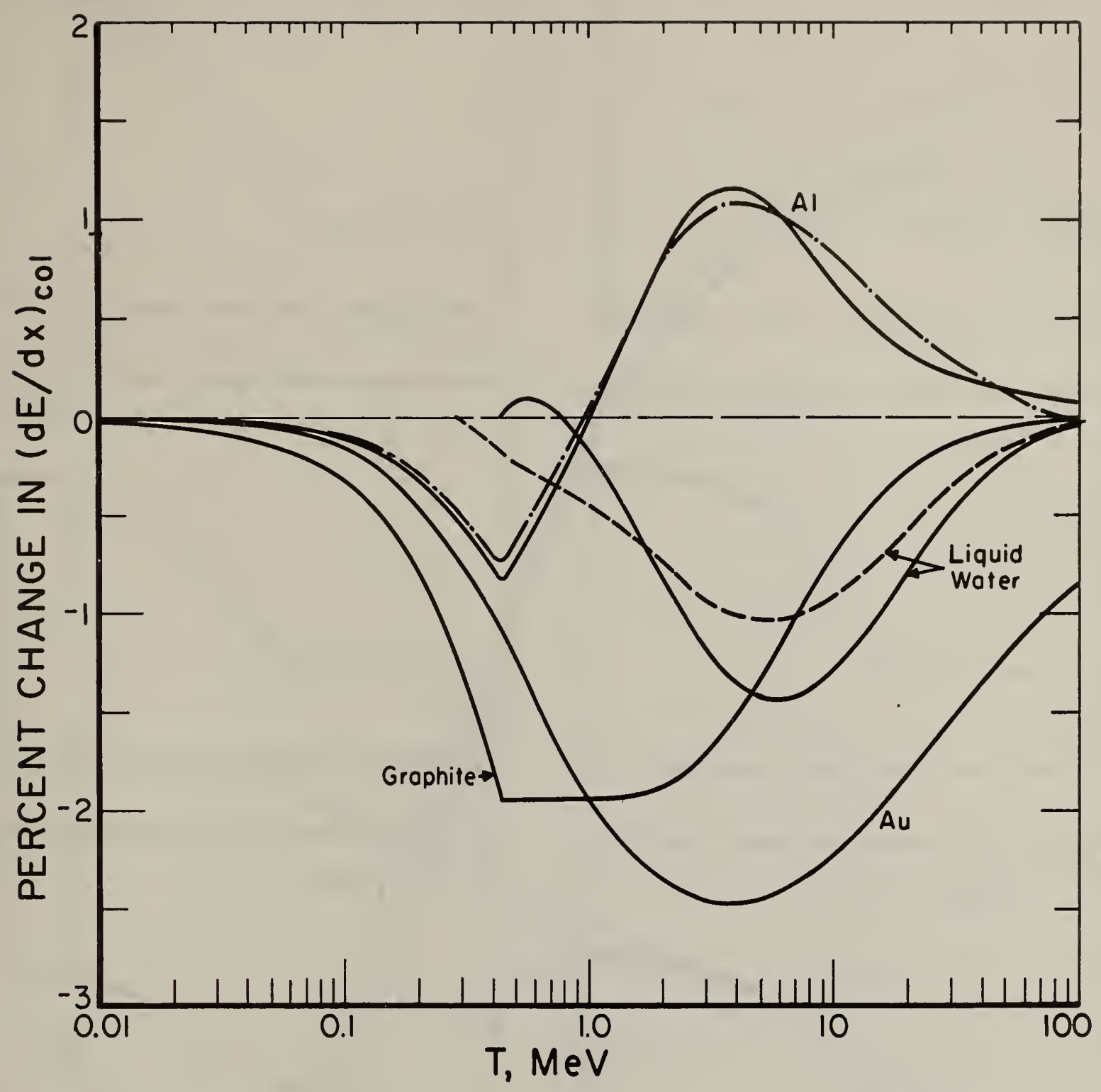

Fig. 2. Percent change in collision stopping power $\left(\frac{d E}{d x}\right)_{\text {col }}$ resulting from the use of the density-effect correction from a new, more accurate, numerical evaluation rather than that calculated according to the algorithm of Sternheimer and Peierls [10]. The solid curves, given as a function of electron kinetic energy $T$, are from the present work evaluated according to Sternheimer's [12] model; the broken curves were derived from experimental information on the dielectric-response function by Inokuti and Smith [13] for aluminum and by Ashley [14] for liquid water. The sharp corners in the curves are due to the approximate cut-off procedure in the Sternheimer-Peierls algorithm. 

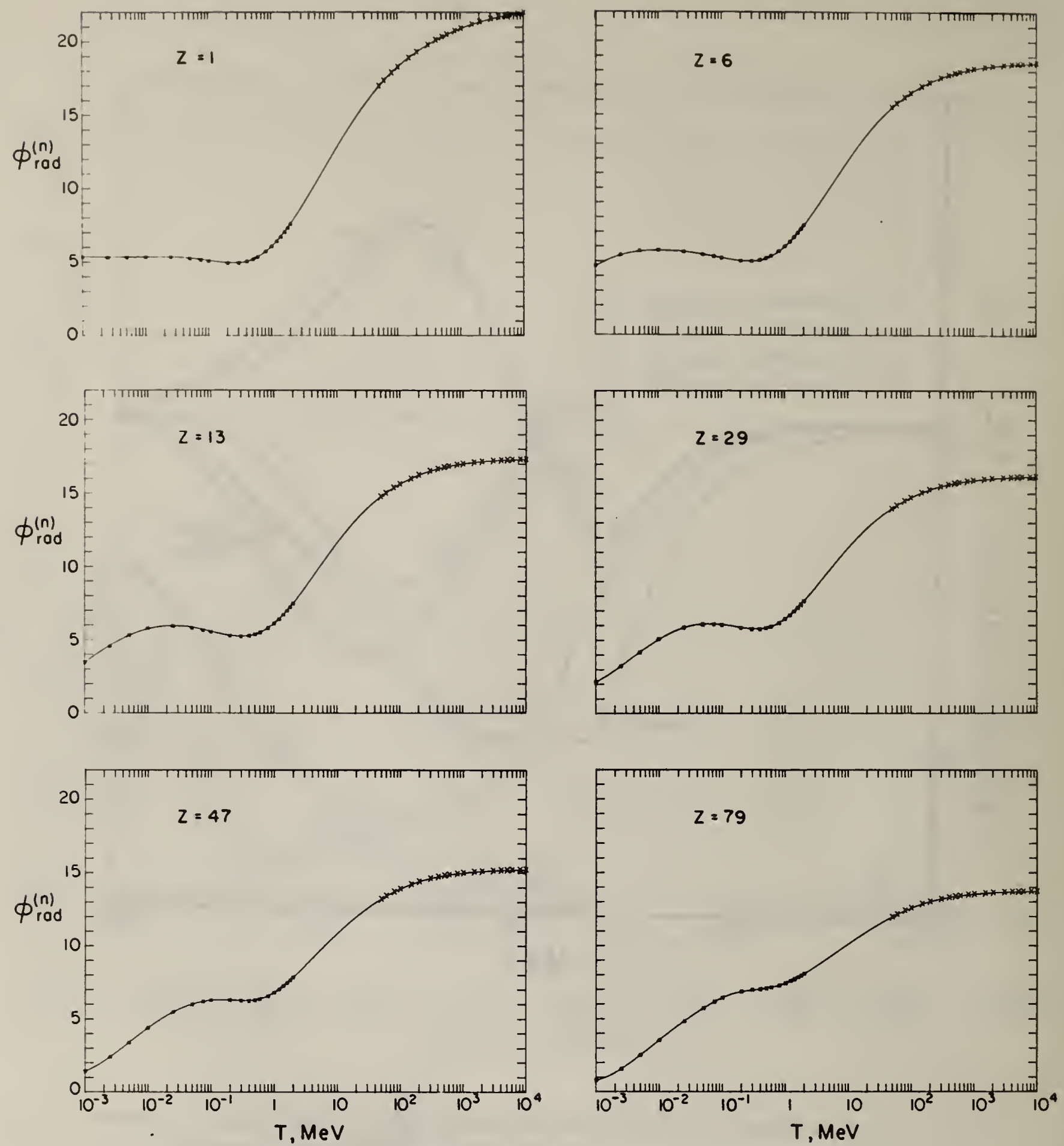

Fig. 3. Radiative energy-loss function $\phi_{\text {rad }}^{(n)}$ for bremsstrahlung in the field of the atomic nucleus. Points below $2 \mathrm{MeV}$ are from the calculations of Pratt et az. [18]; points above $50 \mathrm{MeV}$ were calculated using Bethe-Heitler theory with Hartree-Fock form-factor [55-56] screening corrections and the Coulomb correction of Davies, Bethe, Maximon, and 01sen [17]. Curves are from a least-squares fit to the theoretical points. 


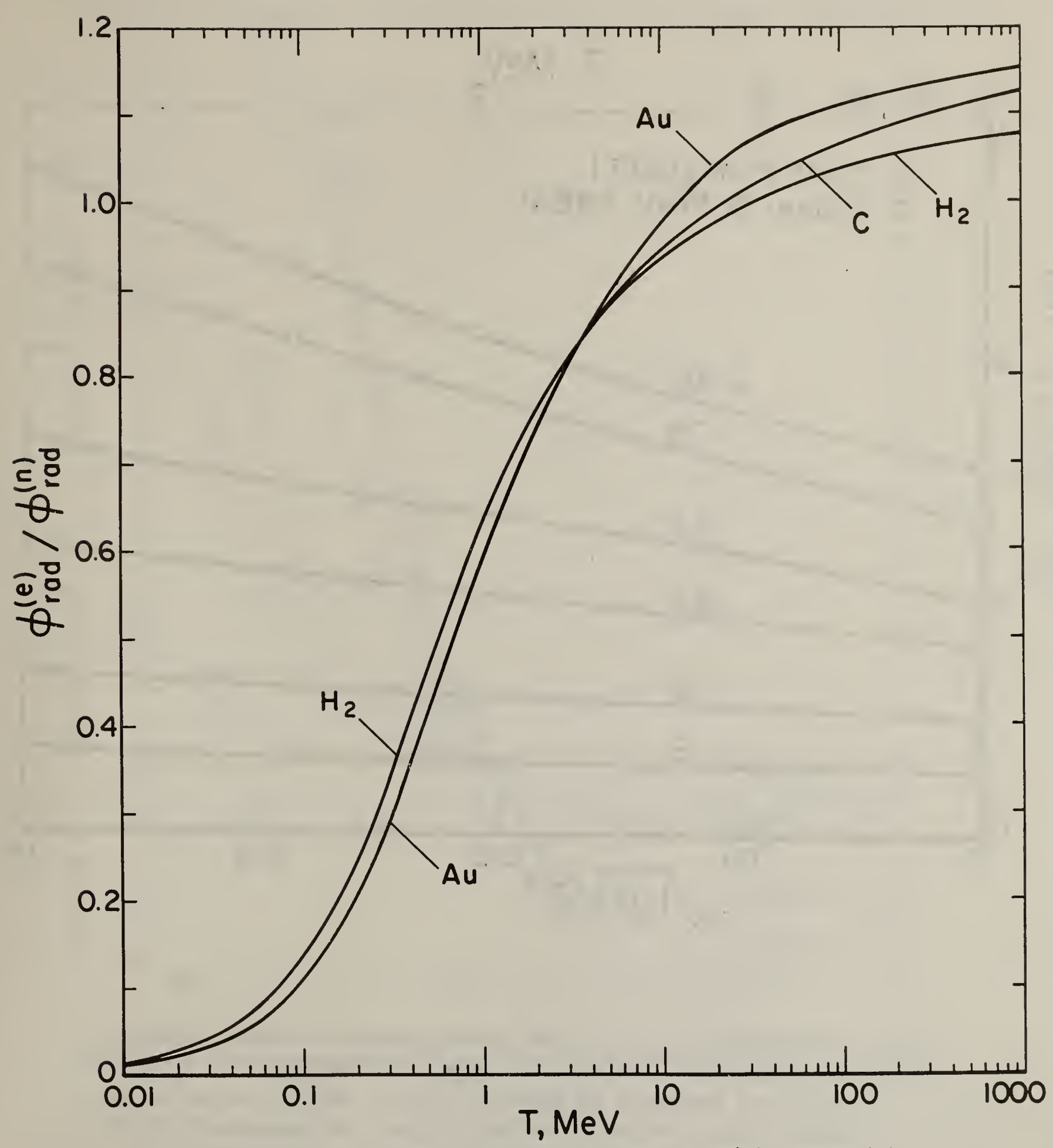

Fig. 4. Ratio of the radiative energy-loss functions $\phi_{\text {rad }}^{(e)}$ and $\phi_{\text {rad }}^{(n)}$ which. represent the mean energy losses resulting from bremsstrahlung emission in the field of the atomic electrons, and the field of the atomic nucleus, respectively. The results for $\phi_{\text {rad }}^{(e)}$ are based on Haug's [20] theory of electron-electron bremsstrahlung with screening corrections evaluated according to Wheeler and Lamb [57] using Hartree-Fock incoherent scattering functions [55]. The total radiative stopping power is proportional to $z^{2} \phi_{\text {rad }}^{(n)}+z \phi_{\text {rad }}^{(e)}$. 


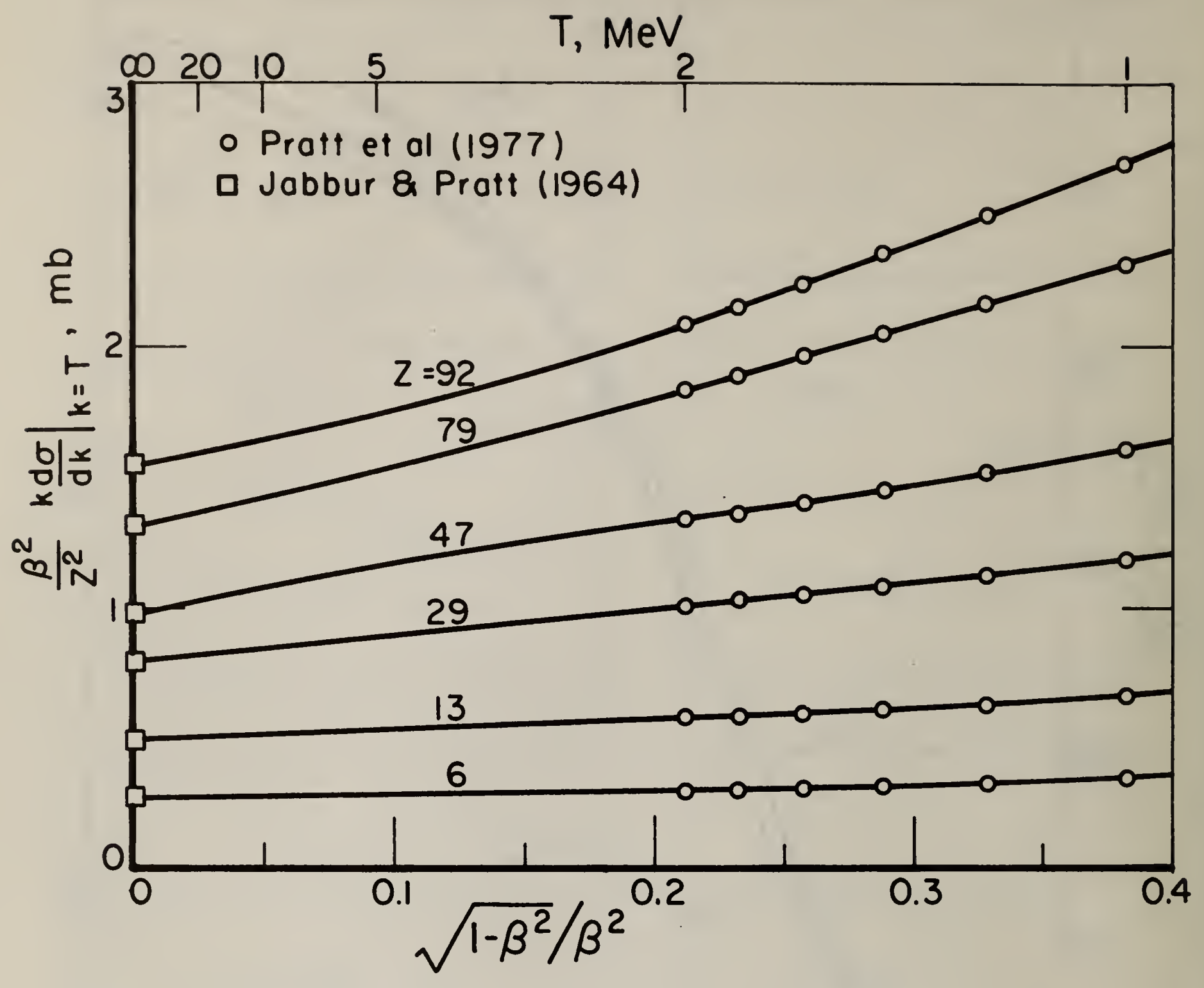

Fig. 5. High-frequency limit (tip) of the electron-nucleus differential bremsstrahlung cross section. The scaled tip value, $\left(\beta^{2} / z^{2}\right) k(d \sigma / d k)$ for $k=T$, is plotted as a function of the variable $\sqrt{1-\beta^{2}} / \beta^{2}$, where $\beta$ is the incident electron velocity divided by the speed of light. The corresponding initial electron kinetic energy is given on the upper scale. The squares are the results of the theory of Jabbur and Pratt [21] for $\beta=1$; the circles below $2 \mathrm{MeV}$ are from the data of Pratt et al. [18]. The curves, nearly straight lines when plotted in terms of these variables, are least-squares fits to the theoretical points. 


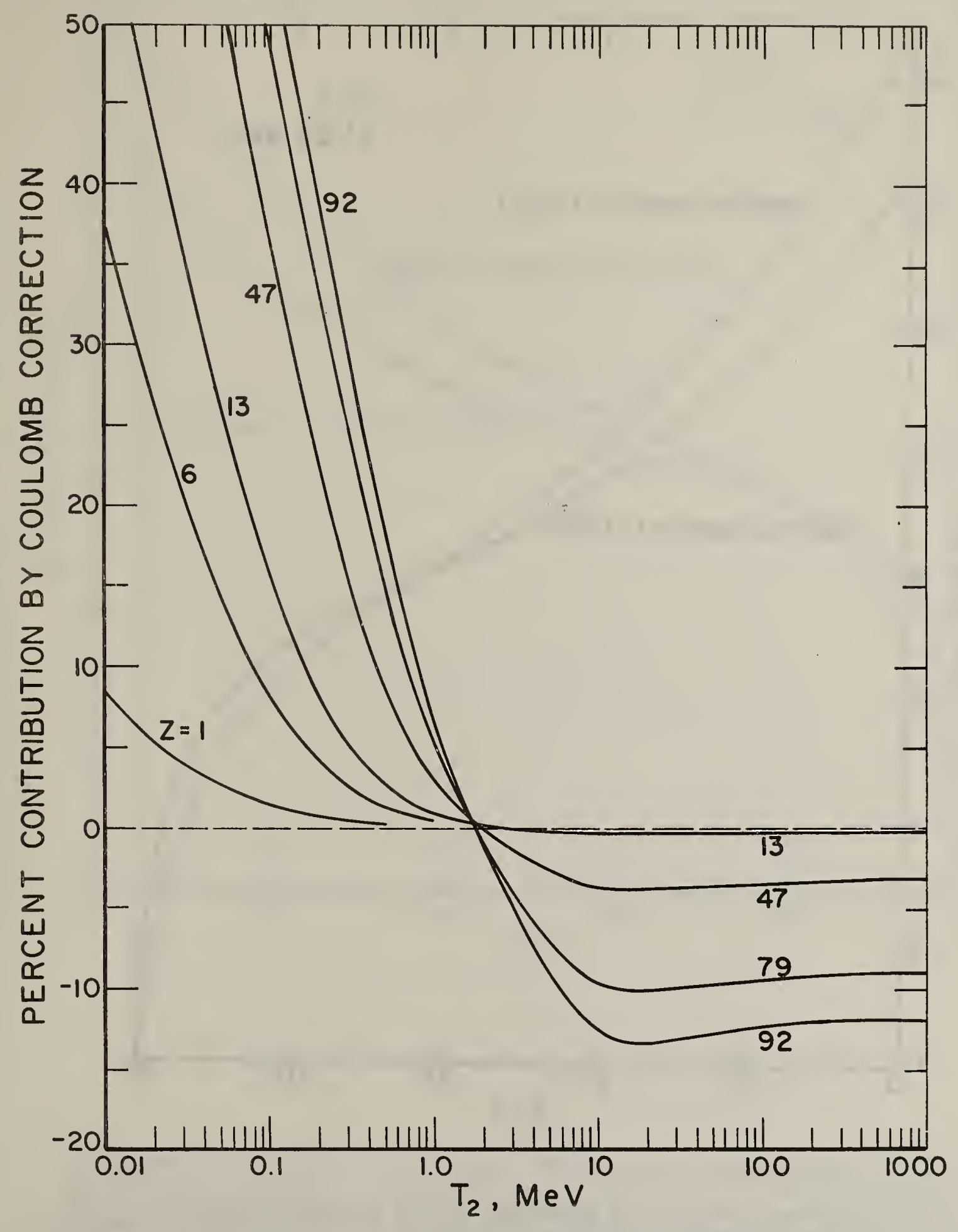

Fig. 6. Contribution of the Coulomb correction to the high-energy electron-nucleus bremsstrahlung cross section differential in emitted photon energy. The percent contribution to the final cross section is given as a function of the final kinetic energy $T_{2}$ of the electron after the emission of a bremstrahlung photon. The results are nearly the same for all initial electron kinetic energies $\gtrsim 50 \mathrm{MeV}$. 


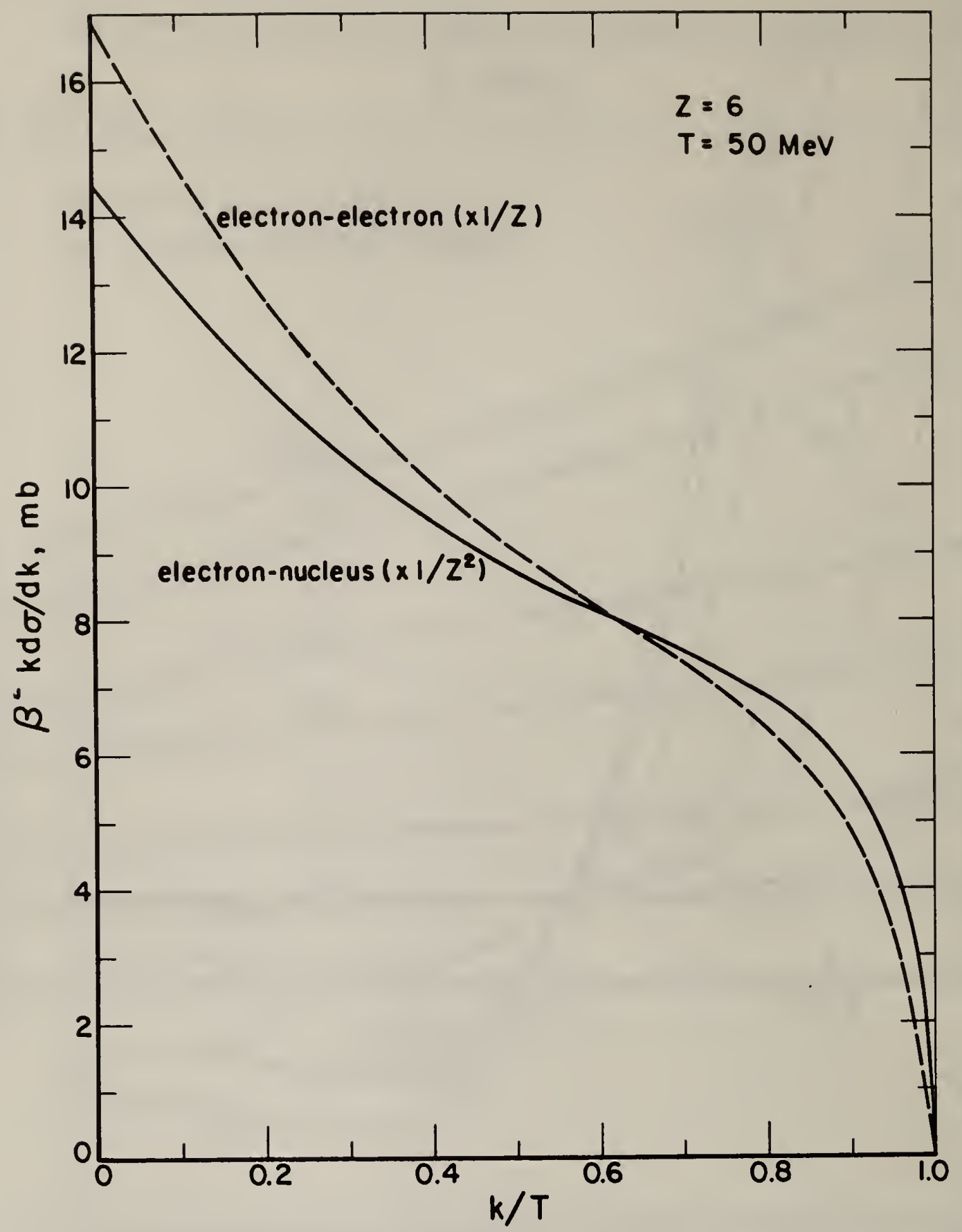

Fig. 7. Bremsstrahlung production cross section, differential in emitted photon energy. Shown is the scaled cross section $\beta^{2} k(d \sigma / d k)$ vs. the ratio $k / T$ of the emitted photon energy to the initial electron kinetic energy. The solid curve is the electron-nucleus cross section divided by $Z^{2}$, and the dashed curve is the electron-electron cross section divided by $Z$, where $Z$ is the atomic number of the target.

a. Carbon $(Z=6), T=50 \mathrm{MeV}$.

For $T=50 \mathrm{MeV}$, the electron-nucleus results are from a synthesis of Bethe-Heitler theory, screening corrections evaluated in the high-energy approximation using HartreeFock atomic form factors $[55,56]$, and a Coulomb correction combining the theoretical results of Davies, Bethe, Maximon, and 01 sen [17] and of Elwert [22], modified to go smoothly into the high-frequency limit given by the theory of Jabbur and Pratt [21]. The electron-electron results are from the theory of Haug [20], with screening corrections evaluated in the high-energy approximation using Hartree-Fock incoherent scattering factors [55]. 


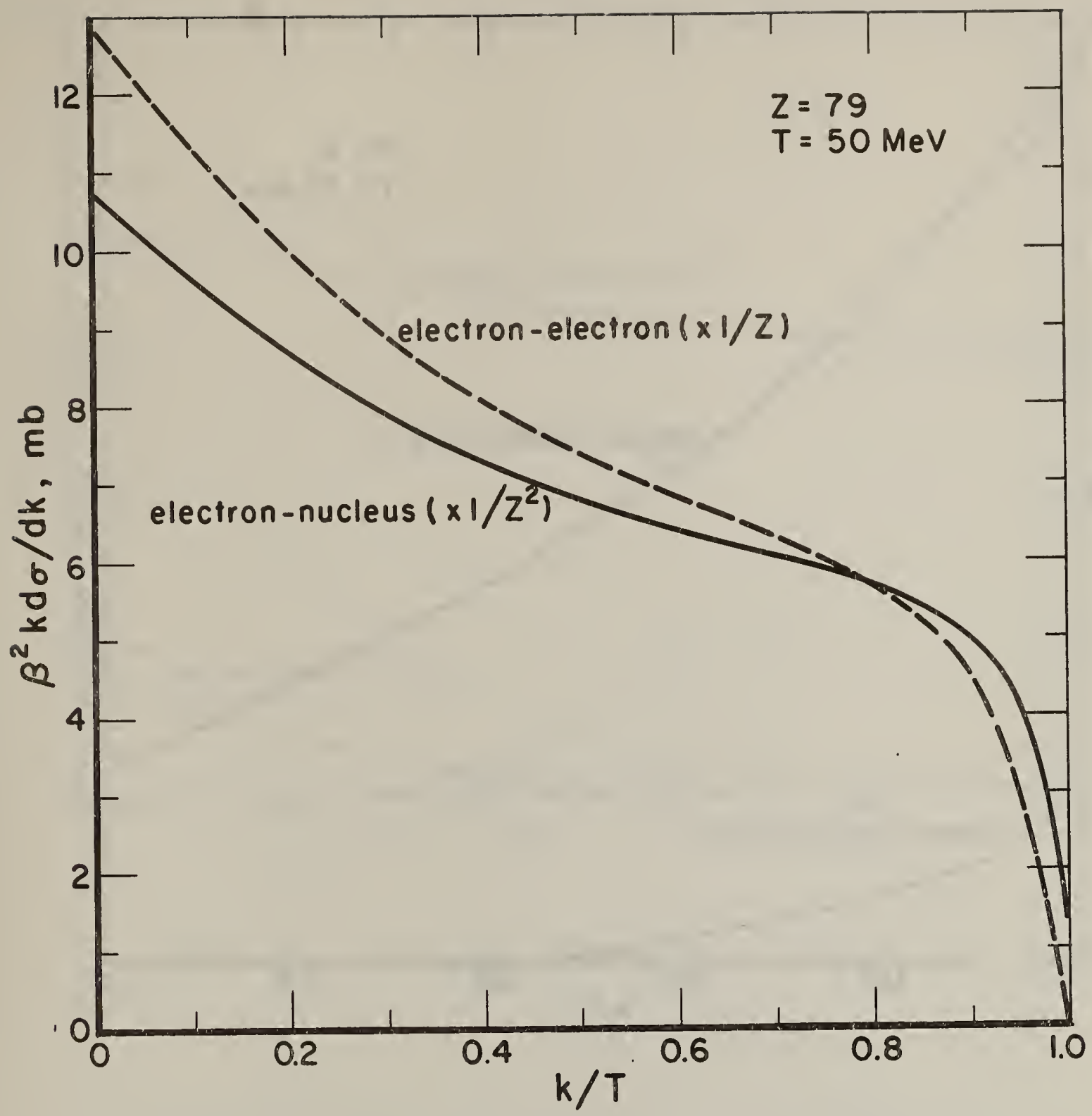

Fig. 7. Bremsstrahlung production cross section, differential in emitted photon energy. Shown is the scaled cross section $\beta^{2} k(d \sigma / d k)$ vs. the ratio $k / T$ of the emitted photon energy to the initial electron kinetic energy. The solid curve is the electron-nucleus cross section divided by $Z^{2}$, and the dashed curve is the electron-electron cross section divided by $Z$, where $z$ is the atomic number of the target.

b. Gold $(Z=79), T=50 \mathrm{MeV}$.

For $T=50 \mathrm{MeV}$, the electron-nucleus results are from a synthesis of Bethe-Heitler theory, screening corrections evaluated in the high-energy approximation using HartreeFock atomic form factors $[55,56]$, and a Coulomb correction combining the theoretical results of Davies, Bethe, Maximon, and 01sen [17] and of ETwert [22], modified to go smoothly into the high-frequency limit given by the theory of Jabbur and Pratt [21]. The electron-electron results are from the theory of Haug [20], with screening corrections evaluated in the high-energy approximation using Hartree-Fock incoherent scattering factors [55]. 


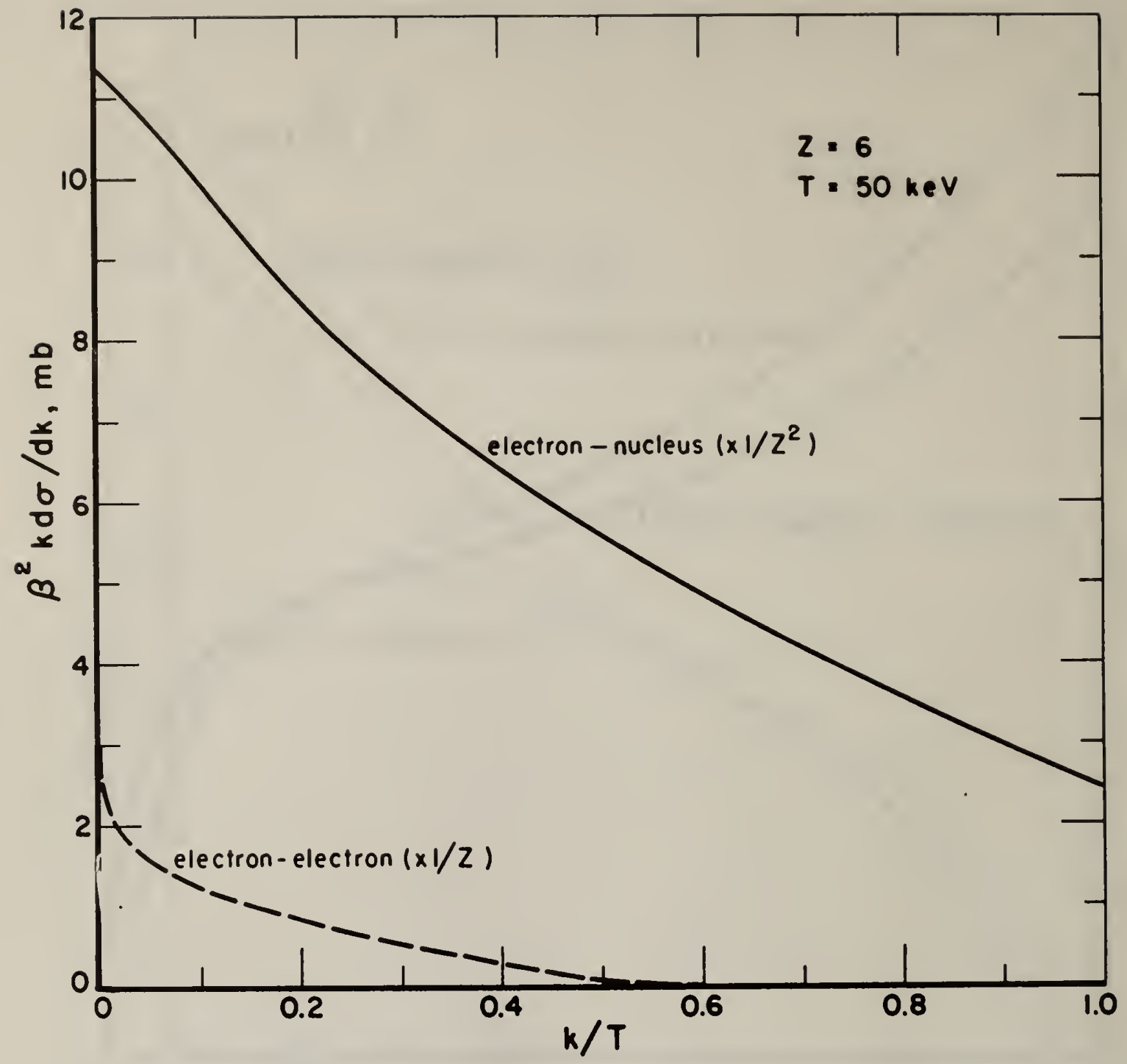

Fig. 7. Bremsstrahlung production cross section, differential in emitted photon energy. Shown is the scaled cross section $\beta^{2} k(d \sigma / d k)$ vs. the ratio $k / T$ of the emitted photon energy to the initial electron kinetic energy. The solid curve is the electron-nucleus cross section divided by $Z^{2}$, and the dashed curve is the electron-electron cross section divided by $Z$, where $Z$ is the atomic number of the target.

c. Carbon $(Z=6), T=50 \mathrm{keV}$.

For $T=50 \mathrm{keV}$, the electron-nucleus results are from the calculations of Pratt et al. [18]. The electron-electron results are from the theory of Haug [20]; screening corrections which would somewhat modify the rather steep portion of the curves near $k=0$ have been neglected. 


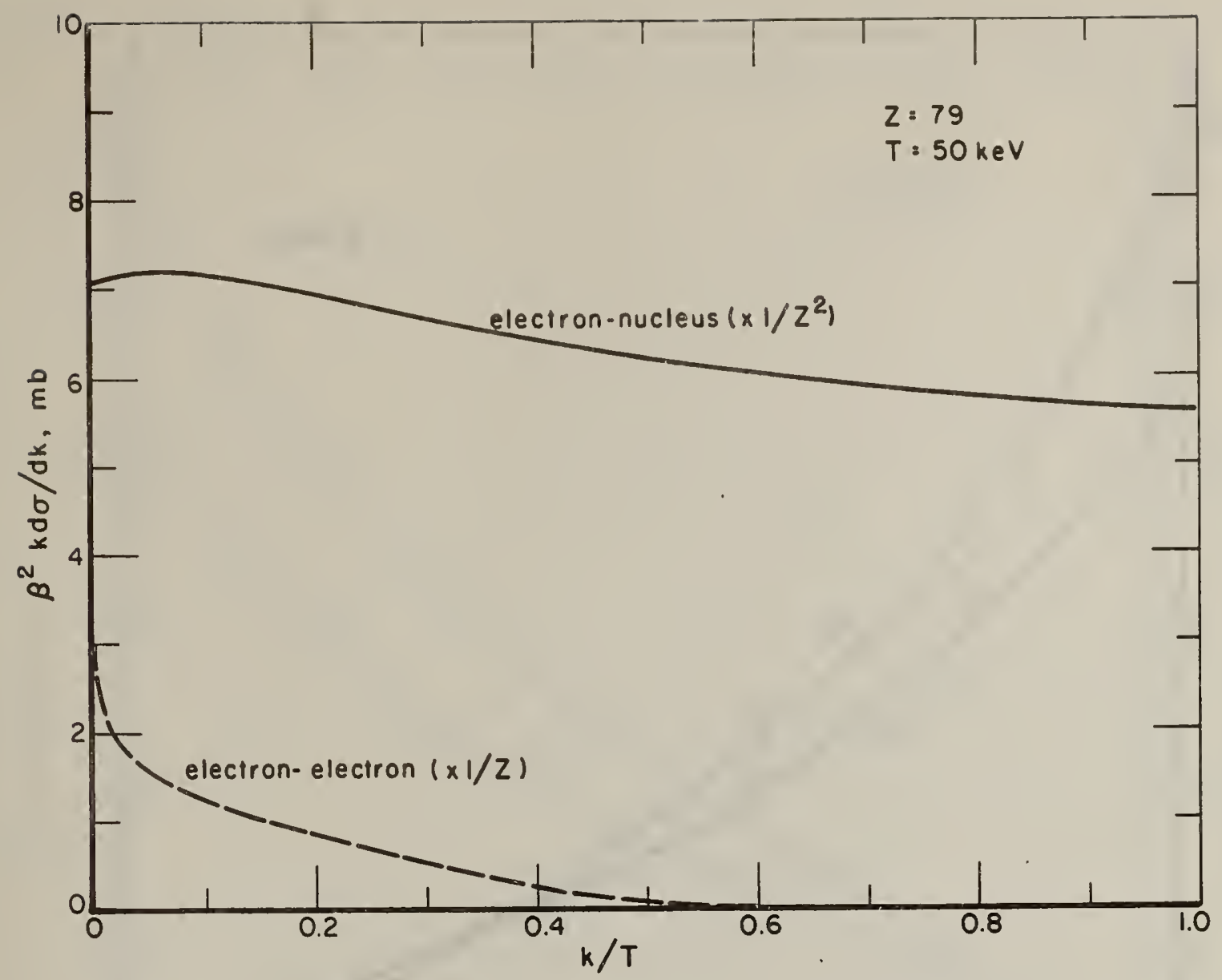

Fig. 7. Bremsstrahlung production cross section, differential in emitted photon energy. Shown is the scaled cross section $\beta^{2} k(d \sigma / d k)$ vs. the ratio $k / T$ of the emitted photon energy to the initial electron kinetic energy. The solid curve is the electron-nucleus cross section divided by $Z^{2}$, and the dashed curve is the electron-electron cross section divided by $Z$, where $z$ is the atomic number of the target.

d. Gold $(Z=79), T=50 \mathrm{keV}$.

For $T=50 \mathrm{keV}$, the electron-nucleus results are from the calculations of Pratt et al.

[18]. The electron-electron results are from the theory of Haug [20]; screening corrections which would somewhat modify the rather steep portion of the curves near $k=0$ have been neglected. 


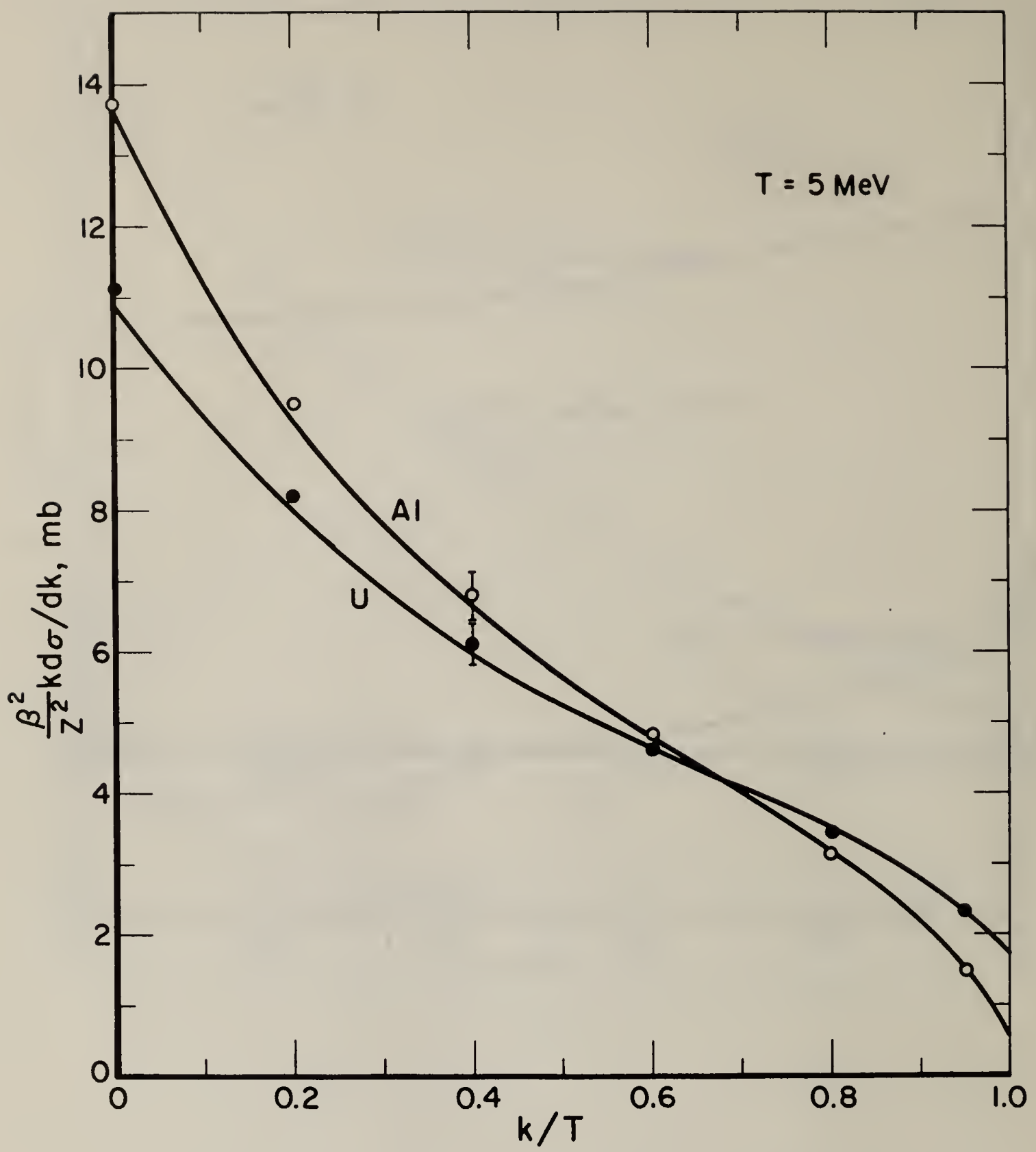

Fig. 8. Comparison of interpolated differential electron-nucleus bremsstrahlung cross sections with the results of exact calculations by Tseng and Pratt [23]. Shown is the scaled cross section $\left(\beta^{2} / Z^{2}\right) k(d \sigma / d k)$ plotted as a function of the ratio $k / T$, where $\beta$ is the ratio of the initial electron velocity to the speed of light, $Z$ is the atomic number of the target, $k$ is the emitted photon energy, and $T$ is the initial electron kinetic energy. The curves are from interpolation between the high-energy results $(T \geqslant 50 \mathrm{MeV})$ and the results of Pratt et az. [18] $(T \leqslant 2 \mathrm{MeV})$. The points are from the pilot calculations of Tseng and Pratt [23]; the error bars are drawn to indicate a $\pm 5 \%$ uncertainty.

a. $\mathrm{Al}$ and $\mathrm{U}, \mathrm{T}=5 \mathrm{MeV}$. 


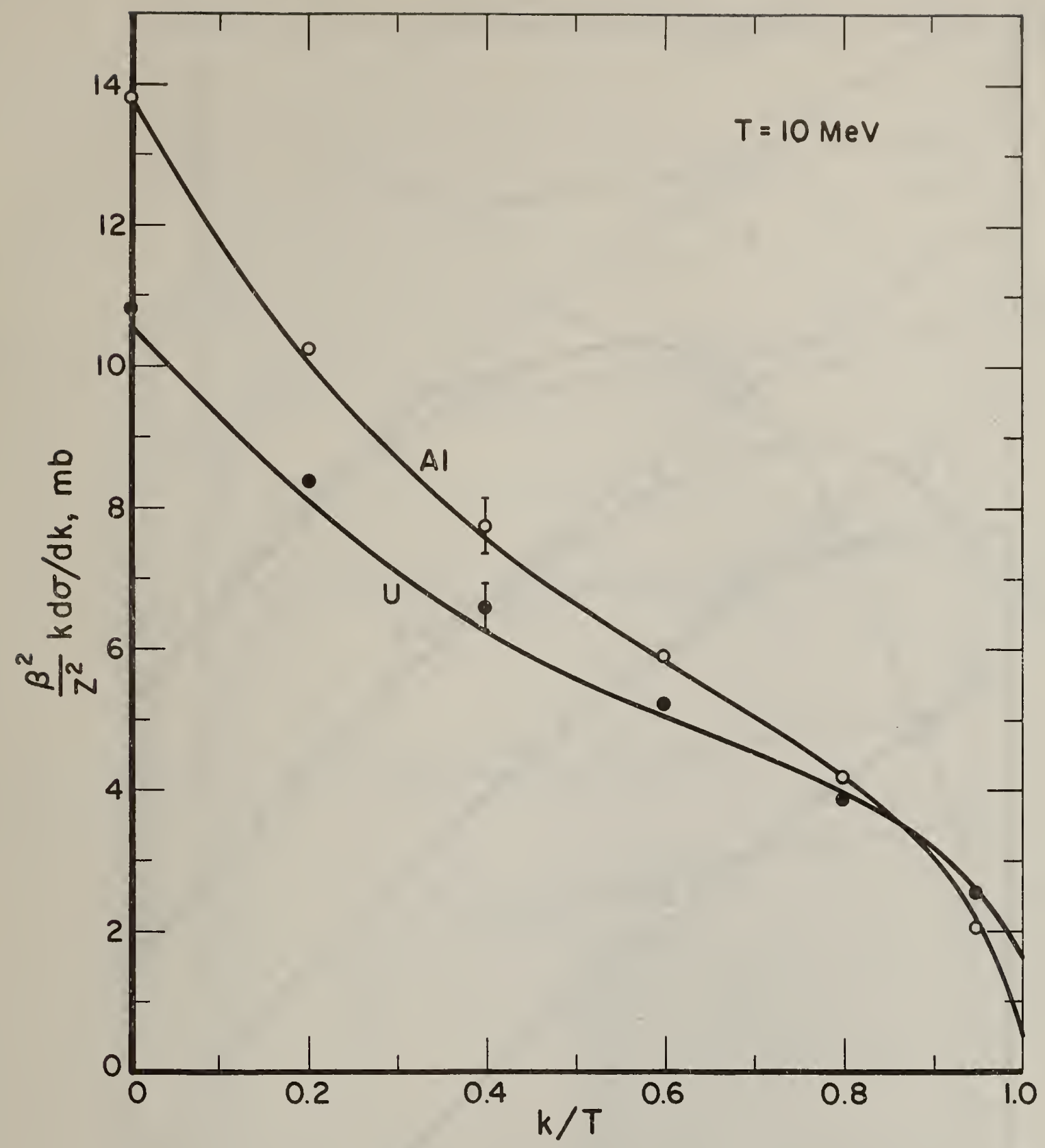

Fig. 8. Comparison of interpolated differential electron-nucleus bremsstrahlung cross sections with the results of exact calculations by Tseng and Pratt [23]. Shown is the scaled cross section $\left(\beta^{2} / z^{2}\right) k(d \sigma / d k)$ plotted as a function of the ratio $k / T$, where $\beta$ is the ratio of the initial electron velocity to the speed of light, $Z$ is the atomic number of the target, $k$ is the emitted photon energy, and $T$ is the initial electron kinetic energy. The curves are from interpolation between the high-energy results $(T \geqslant 50 \mathrm{MeV})$ and the results of Pratt et az. [18] $(T \leqslant 2 \mathrm{MeV})$. The points are from the pilot calculations of Tseng and Pratt [23]; the error bars are drawn to indicate a $\pm 5 \%$ uncertainty.

b. Al and $U, T=10 \mathrm{MeV}$. 


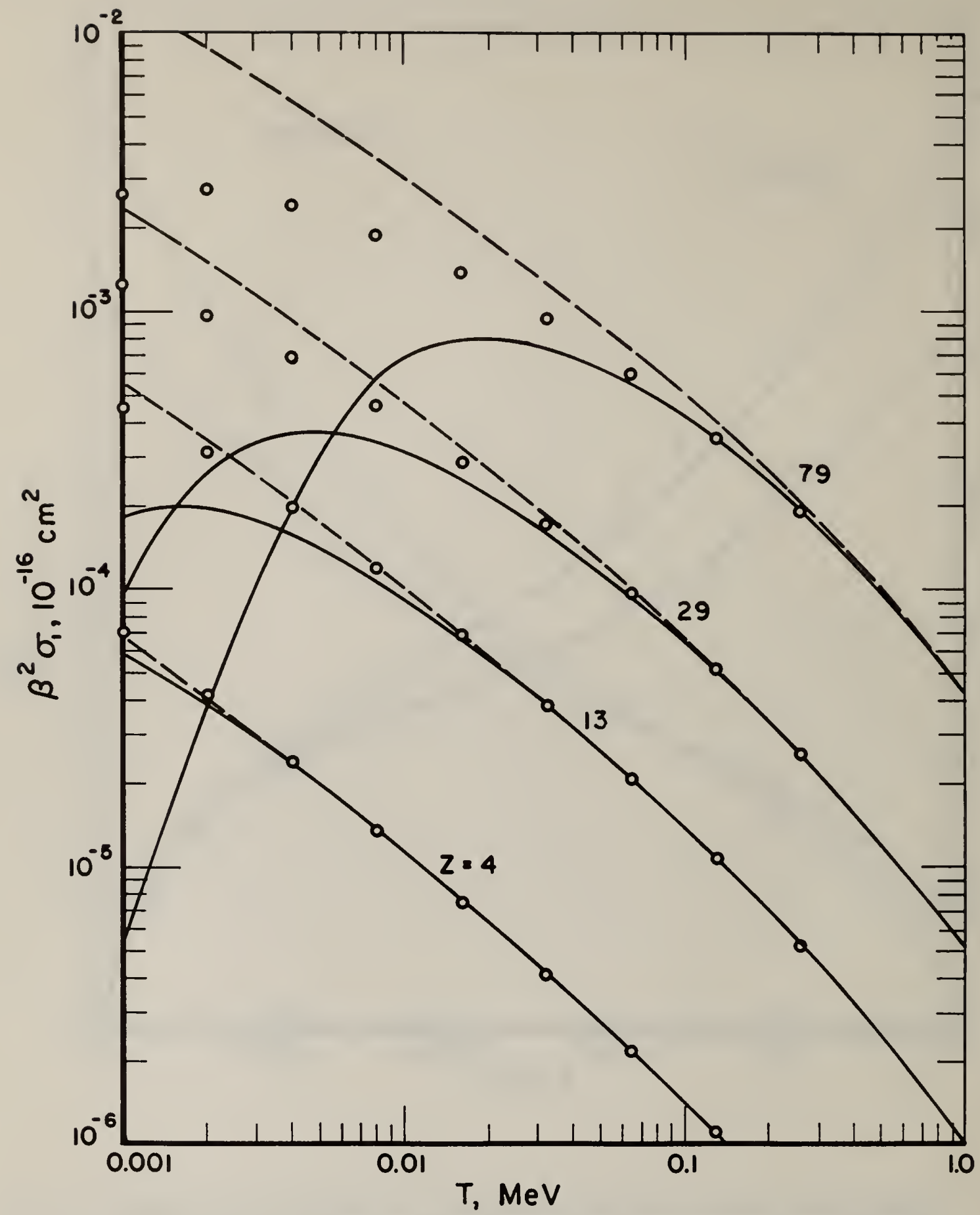

Fig. 9. Transport cross sections for elastic scattering, at electron energies below $1 \mathrm{MeV}$. The quantity given is $\beta^{2} \sigma_{1}(T)$, where $\beta$ is the ratio of the electron velocity to the speed of light, and $\sigma_{1}(T)=2 \pi \int_{0}^{\pi}[d \sigma(\theta, T) / d \Omega](1-\cos \theta) \sin \theta d \theta$. The curves are results based on the factorization of $d \sigma / d \Omega$ (Mott cross section $x$ screening correction). The solid curves are for a screening correction calculated with a screening parameter according to Moliere [26]. The dashed curves are with a screening correction in terms of a form factor, $(1-F)^{2}$. The points are from the results of the phase-shift calculations of Riley et al. [28] for a static, screened Coulomb potential. 


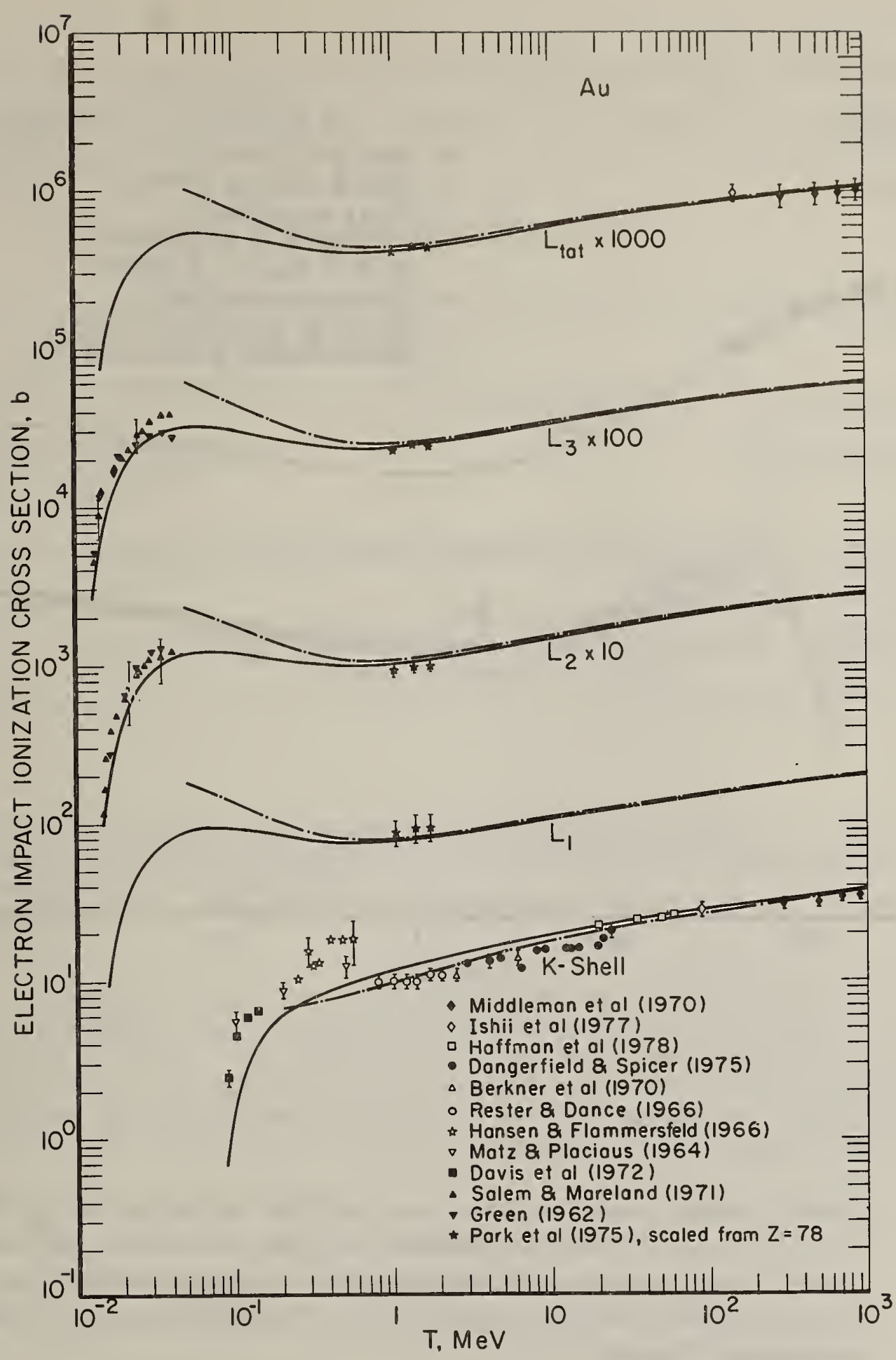

Fig. 10. Comparison of theoretical electron impact ionization cross sections for $K$ and $L$ shells in gold with experimental results. The solid curves are from our Weizsäcker-Williams calculations, and the broken curves are from Scofield's [32] Born-approximation calculations. The points are from various measurements [33-44]. 


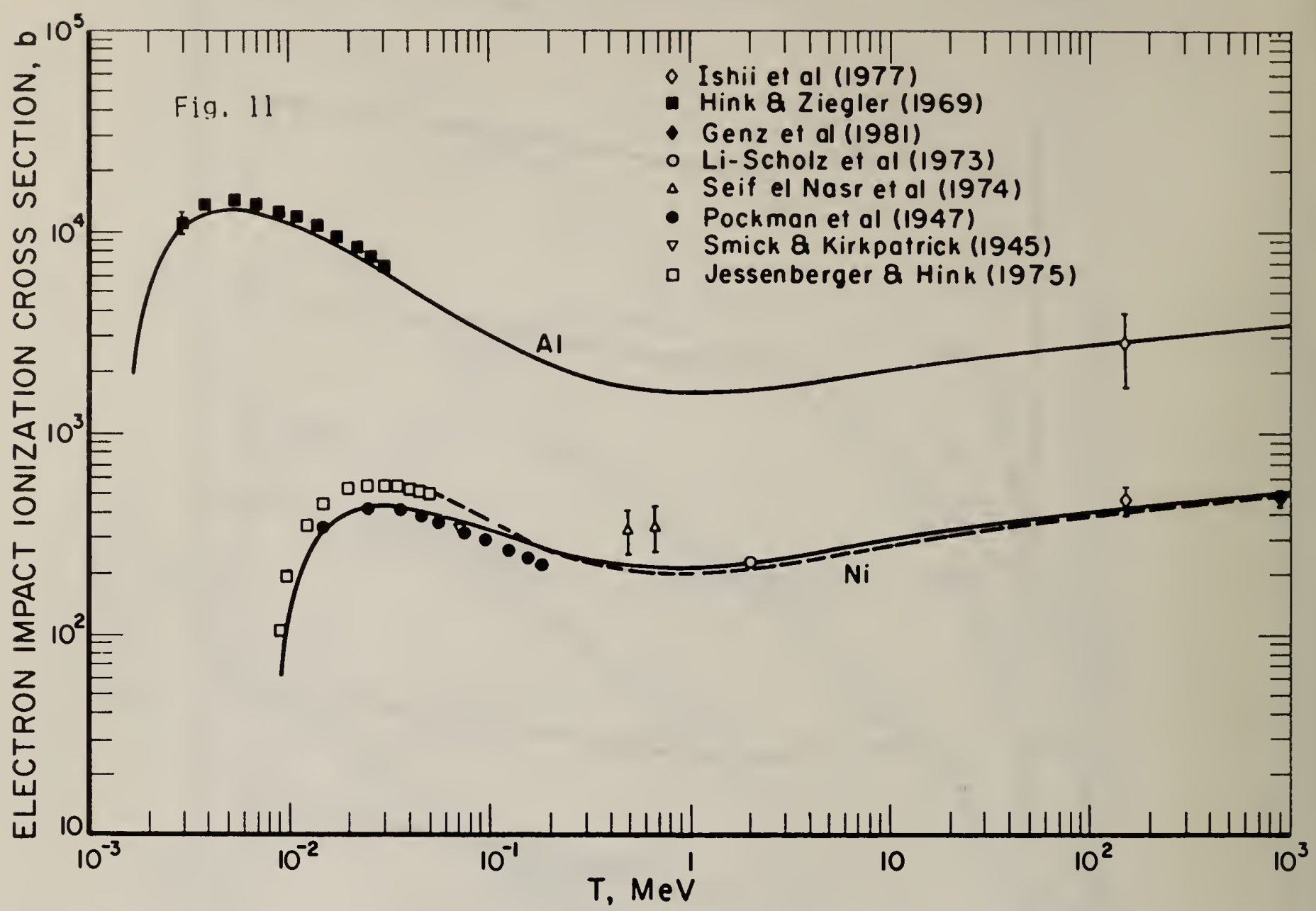

Fig. 11. K-shell electron impact ionization cross sections in aluminum and nickle. The solid curves are from our Weizsäcker-Williams calculations; the broken curve is from Scofield's [32] Born-approximation calculations (Scofield did not calculate the cross section for $A l)$. The points are from various measurements $[34,45-51]$. 
BIBLIOGRAPHIC DATA NBSIR $82-2572$

SHEET (See instructions)

4. TITLE AND SUBTITLE

\section{STATUS OF ELECTRON TRANSPORT CROSS SECTIONS}

5. AUTHOR(S)

S. M. Seltzer and M. J. Berger

6. PERFORMING ORGANIZATION (If joint or other than NBS. see instructions)

7. Contract/Grant No.

NATIONAL BUREAU OF STANDARDS

DEPARTMENT OF COMMERCE

WASHINGTON, D.C. 20234

9. SPONSORING ORGANIZATION NAME AND COMPLETE ADDRESS (Street. City, State, ZIP)

Office of Health and

Office of Naval Research

Arlington, Virginia 22217

Space Science Data Center

NASA Goddard Space Flight Center Greenbeit, Maryiand 20771
Environmental Research

Department of Energy

Washington, D.C. 20545

10. SUPPLEMENTARY NOTES

[.] Document describes a computer program; SF-185, FIPS Software Summary, is attached.

11. ABSTRACT (A 200-word or less factual summary of most significant information. If document includes a significant bibliography or literature survey, mention it here)

This report describes recent developments and improvements pertaining to cross sections for electron-photon transport calculations. The topics discussed include: (1) electron stopping power (mean excitation energies, density-effect correction); (2) bremsstrahlung production by electrons (radiative stopping power, spectrum of emitted photons); (3) elastic scattering of electrons by atoms; (4) electron-impact ionization of atoms.

12. KEY WORDS (Six to twelve entries; alphabetical order; capitalize only proper names; and separate key words by semicolons) bremsstrahlung; cross sections; elastic scattering; electron-impact ionization; electrons; photons; stopping power; transport.

\section{AVAILABILITY}

Cunlimited

For Official Distribution. Do Not Release to NTIS

Order From Superintendent of Documents, U.S. Government Printing Office, Washington, D.C. 20402.

[X Order From National Technical Information Service (NTIS), Springfield, VA. 22161
14. NO. OF

PRINTED PAGES

30

15. Price

$\$ 7.50$ 

